\title{
THE EFFECTS OF SODIUM ANTIMONY TARTRATE ON THE MYOCARDIUM
}

\author{
BY \\ M. HONEY* \\ From the Cardiac Department, University College Hospital
}

Received February 24, 1960

Sodium antimony tartrate (S.A.T.) has been used in the treatment of Schistosomiasis since 1918 (Christopherson, 1918, 1919) and is still the most effective drug (Adams and Maegraith, 1953; Manson-Bahr, 1954; Goodman and Gilman, 1956), though different workers vary widely in the details of the courses of treatment employed: it is used as a routine at the Hospital for Tropical Diseases (H.T.D.). Trivalent antimony compounds, especially S.A.T. and tartar emetic, are toxic drugs and may cause unpleasant side-effects (Christopherson, 1918; Khalil, 1935; Alves and Blair, 1946; Girgis and Aziz, 1948; Rail, 1949), including headache, nausea and vomiting, diarrhœa, fever, muscle and joint pains, hepatitis, and skin eruptions: injections may cause pain along the vein, a metallic taste in the mouth, a sense of constriction in the chest, paroxysms of coughing, syncopal attacks, or severe and even fatal reactions of an anaphylactic type (Fakhry, 1931; War Medicine, 1945). Death may also result from hepatitis (Jopling, 1949) or may occur suddenly at a time unrelated to an actual injection (Mainzer and Krause, 1940; Ch'ien Teh and Lin Yu-K'un, 1957).

Case 1. A West African girl, aged 23, attended hospital in December, 1956, with an itchy papular eruption on the neck, right upper chest, and epigastrium, which had been present for six months; she gave a history of hæmaturia due to a $S$. hamatobium infestation which had been treated with a course of intramuscular injections nine years previously. A biopsy of a skin lesion revealed a nest of viable ova of $S$. hamatobium, so she was referred to Sir George McRobert and was admitted to the H.T.D. There was no other clinical abnormality. Examination of terminal urine and rectal snips for Schistosome ova was negative, but the Schistosomal complement fixation test was strongly positive. Treatment was started with daily intravenous injections of S.A.T., a total dose of 29 grains $(1.9 \mathrm{~g}$.) being given in 18 days; during the last 3 or 4 days of treatment she had anorexia, nausea, vomiting, and muscle pains. The last injection was in the morning, and the same evening the pulse rate was noted to be slow (45 a minute), and at 10 p.m. she suddenly became unconscious, with fixed dilated pupils, trismus, opisthotonus, and jerking movements of the head. At the end of the attack the pulse was regular at 120 a minute. The next morning, an electrocardiogram showed gross abnormalities (Fig. 1): normal sinus rhythm (97 a minute); tall very broad $P$ waves in leads II, III, and aVF (duration 0.16 sec., amplitude $0.30-0.35 \mathrm{mV}$ ); very low voltage QRS in leads I and aVL, with elevated S-T segment in these leads and in V3 and V5; prolonged Q-T duration ( $0.44 \mathrm{sec}$.); low or biphasic $\mathrm{T}$ waves merged with elevated $\mathrm{S}-\mathrm{T}$ segments. Fifteen minutes later, she complained of severe sub-sternal oppression and became shocked: the pulse was irregular and the B.P. 90/60. She had several further brief episodes of unconsciousness with convulsion, thought to be Stokes-Adams attacks, and the following day a cardiogram (Fig. 1) showed a chaotic rhythm, with only occasional recognizable sinus beats and very numerous bizarre, multifocal ventricular ectopic beats and short bursts of rapid (200 a minute) ventricular tachycardia. Clinically her condition suggested a recent severe myocardial infarction and the first cardiogram was consistent with an anterior infarct, though there were no pathological $Q$ waves: her age and sex were however against this diagnosis and it seemed probable that her condition was to be attributed

*Present address: Cardiac Department, St. Bartholomew's Hospital. A demonstration based on this investigation was presented at the British Cardiac Society meeting at Cardiff, April, 1959. 
to toxic effects of S.A.T. She was treated with quinidine and digitalis, and there was only one further "dizzy spell", normal rhythm being rapidly restored and her subsequent progress being uneventful. Serial cardiograms showed a return towards normal and a final record, 7 months later, was normal (Fig. 1).

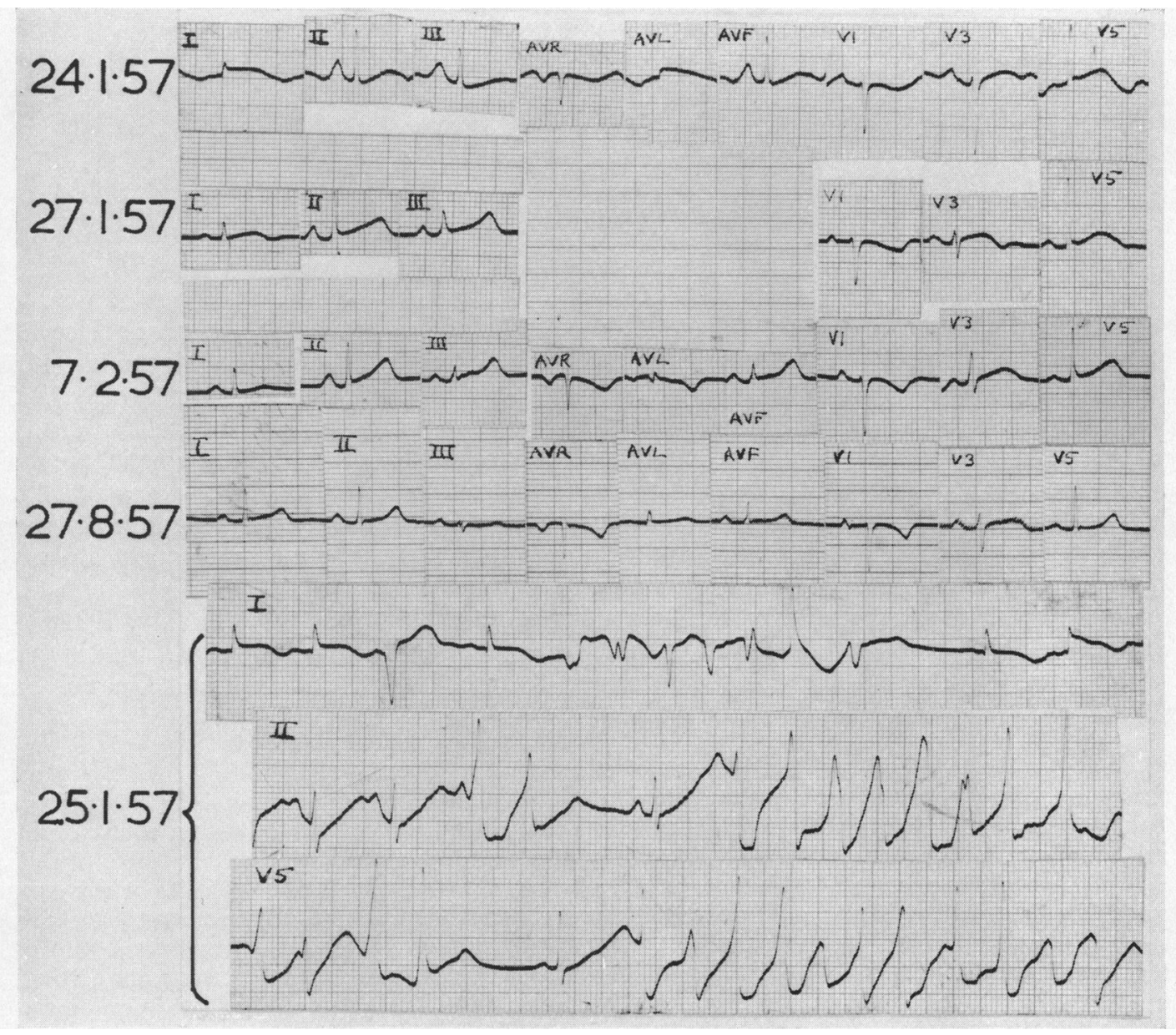

FIG. 1.-Case 1. West African woman, aged 23. Serial electrocardiograms following completion of S.A.T. course. Top record one day after last injection grossly abnormal. Bottom record one day later, showing multifocal ventricular tachycardia. Records 2 days, 2 weeks, and 7 months later, showing progressive return to normal.

As a result of this alarming experience, it was decided to undertake a study of the electrocardiographic changes during and after treatment with S.A.T. in a series of patients with schistosomiasis, the overwhelming majority of whom would be expected to show no clinical evidence of serious cardiovascular complications. It was hoped also to obtain information about which patients might be expected to show serious abnormalities, and in the unfortunate event of a further episode similar to the one described above, it would be instructive to observe the nature of the cardiographic changes leading up to it. It should, however, be stated that, with careful attention to detail, over 100 courses of S.A.T. had been given at the H.T.D. during the past five years without any serious or fatal reaction (Schofield, 1957). 


\section{MATERIAL AND METHODS}

Between February, 1957 and December, 1958, every patient with schistosomiasis starting treatment with S.A.T. had a preliminary cardiogram and a further record at the end of the course, usually within 24 hours of the last injection. Fifty-nine patients (Cases 2-60; Table I)* were studied; all were in-patients. Seven of these had also between one and fourteen serial records during treatment, and three had records made immediately before and again immediately after an S.A.T. injection. During this period, 6 patients (Cases 61-66) started courses of treatment that for various reasons were not completed (see later). In 37 patients, cardiograms were recorded later, in the majority at about six weeks after the end of treatment when they attended the out-patient department for routine follow-up.

The diagnosis of schistosomiasis was based on clinical findings, the discovery of Schistosome ova in terminal or 24-hour urines, stool specimens, or rectal snips taken at sigmoidoscopy, on the presence of a positive complement fixation test in an untreated patient, and in some cases on the findings at cystoscopy. The parasite was $S$. Mansoni in 29 cases, S. hrematobium in 17, both $S$. Mansoni and S. hrematobium in 3, $S$. intercalatum in 1, and unknown in 9 . All patients had a full history taken and clinical examination made from the point of view of possible pre-existing heart disease. With one possible exception, none had signs suggestive of organic heart disease.

A routine course of treatment consisted of 25 to 31 grains ( 1.6 to $2.0 \mathrm{~g}$.) of sodium antimony tartrate (containing a total of 640 to $794 \mathrm{mg}$. of antimony) in daily intravenous injections; $\frac{1}{2}$ grain $(30 \mathrm{mg}$.) is given on the first day, 1 grain $\left(65 \mathrm{mg}\right.$.) on the second, $1 \frac{1}{2}$ grains $(100 \mathrm{mg}$.) on the third and 2 grains $(130 \mathrm{mg}$.) on the fourth and subsequent days; the dose is diluted to $20 \mathrm{ml}$. with distilled water and given over ten minutes. Sometimes, in the event of troublesome side-effects, a rest-day may be allowed, the daily dose may be reduced slightly or the course completed when rather less than the full dose has been given; a smaller total dose was given to young or small patients (details of total dose and duration of course are given in Table I).

In all cases, 12 leads were used, comprising three standard and three augmented unipolar limb leads and the unipolar præcordial leads V1 to V6. A Cambridge direct-writing electrocardiograph (single or three channel) was used. Patients were semi-recumbent, and cardiograms taken during treatment were usually recorded in the mid-morning. Sensitivity was normally adjusted to give $10 \mathrm{~mm}$. deflection for $1 \mathrm{mV}$, and a l-mV standardization was recorded with each lead.

In reading the cardiograms note was made of the amplitude and shape of the $P$ waves, the duration of the P-R interval, measured in the lead (usually standard lead II) where this appeared to be longest, the QRS axis in the standard leads, electrical position, QRS voltage in the præcordial leads, the shape and level of the S-T segment, the amplitude and direction of the T waves, and the Q-T duration. QTc was calculated using the formula of Taran and Szilagyi (1947) in which QTc $=Q T / \sqrt{ }$ cycle length.

Pre-treatment cardiograms were strictly normal in 33 cases and minor abnormalities were noted in 26. Right bundle-branch block was present in one (Case 14) and incomplete R.B.B.B. in four cases. Voltage changes in the præcordial leads, suggestive of slight left ventricular hypertrophy, were present in ten cases. In two (e.g. Fig. 3) the S-T segments were abnormally elevated (but concave with upright $T$ waves) in several leads; in two others (Case 31, aged 9, and Case 30, a Nigerian, aged 23), slightly elevated S-T segments were associated with inverted $\mathrm{T}$ waves in the right præcordial leads. In all three children under 10 years (Cases 28, 31, 38), $\mathrm{T}$ waves were inverted in $\mathrm{V} 2$ and $\mathrm{V} 3$ as well as in $\mathrm{V} 1$; Case 30 had a slightly inverted $\mathrm{T}$ in $\mathrm{V} 2$ and a biphasic (-+) $\mathrm{T}$ in V3. In one case there was a low biphasic $\mathrm{T}$ in lead I (Case 16). The P-R interval was within normal limits in all cases. The Q-T duration was slightly prolonged above the upper limit of normal for the rate (Ashman and Hull, 1937) in 18 and moderately prolonged in 1 (Case 14 with R.B.B.B.).

\section{RESULTS}

In all but 1 of the 59 patients, electrocardiographic changes were seen at the end of the course of S.A.T.; they varied from very slight (and sometimes still within normal limits) to severe changes that, in the absence of a history of S.A.T. administration, would be interpreted as indicating severe myocardial disease.

$P$ wave, $P-R$ interval, and $Q R S$. Case 1 (q.v.) showed tall, broad, but not bifid $P$ waves in some leads, which subsequently reverted to normal, and significant lowering of the $R$ wave voltage in

* For reasons of space Table I has been omitted, but is available on application to the author. 
leads I and aVL. Minor changes of QRS axis occurred in 7 patients. Otherwise there was no change in $\mathrm{P}, \mathrm{P}-\mathrm{R}$ interval, or QRS. No pathological $\mathrm{Q}$ waves were seen.

$S-T$ segment and $T$ wave. (Fig. 2-5). The most characteristic abnormalities observed during S.A.T. treatment are seen in the $\mathrm{S}-\mathrm{T}$ segment and $\mathrm{T}$ wave. The first change to be seen, and the only change in the mildest cases, is a reduction in amplitude of the $T$ wave in all leads. At first this is only slight, so that the tracing remains within normal limits, but as it progresses the left ventricular leads in particular may become frankly abnormal, with $T$ wave voltage in lead I less than $1 \mathrm{~mm}$. $(0.1 \mathrm{mV})$ : both upstroke and downstroke of $\mathrm{T}$ become more gradual and prolonged. Later, notably

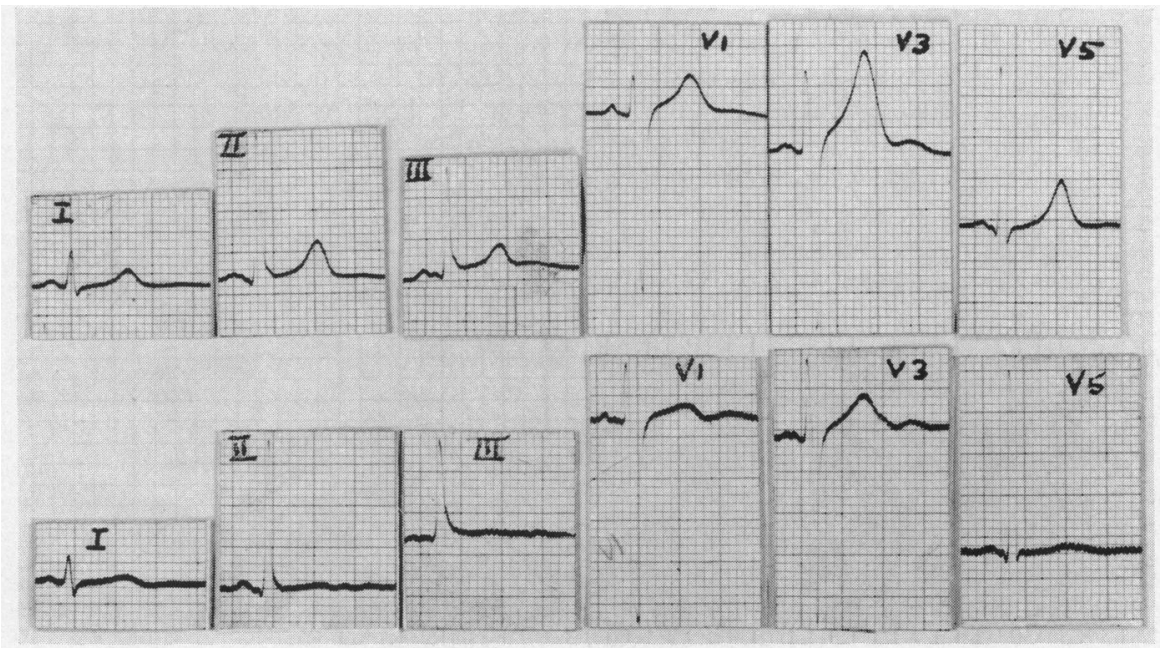

FIG. 2.-Grade II cardiographic changes. Upper record, before treatment; lower record, at end of course of S.A.T. Case 24. European boy, aged 17.

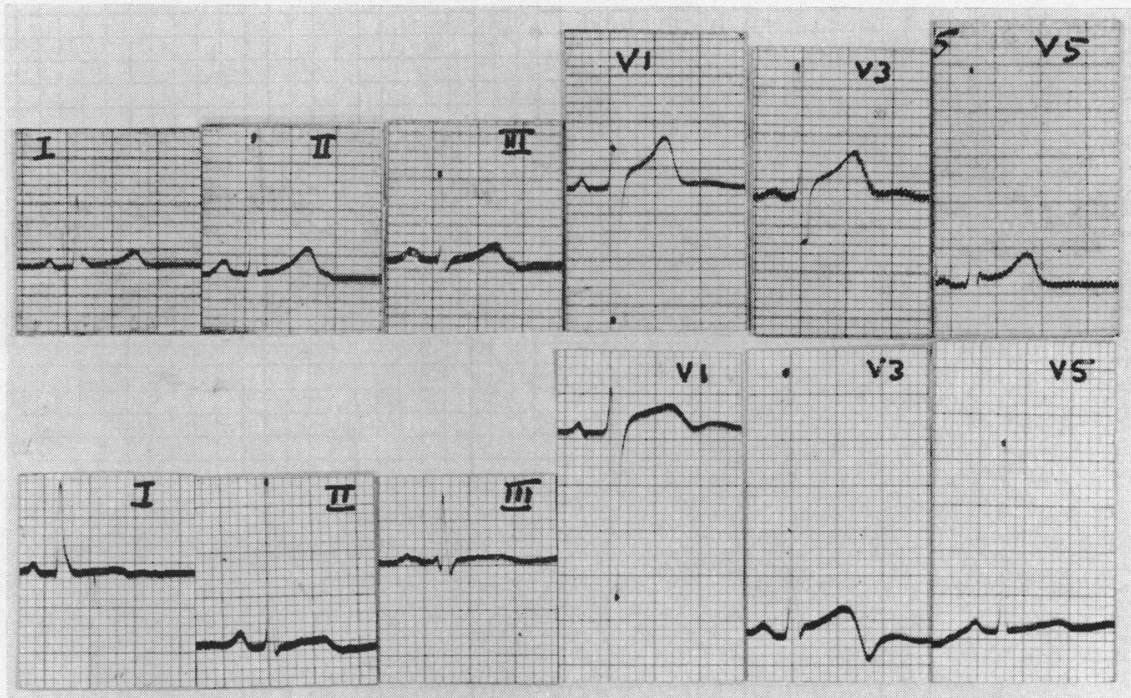

FIG. 3.-Grade III cardiographic changes. Upper record, before treatment; lower record, at end of course of S.A.T. Case 46. West African man, aged 19. 


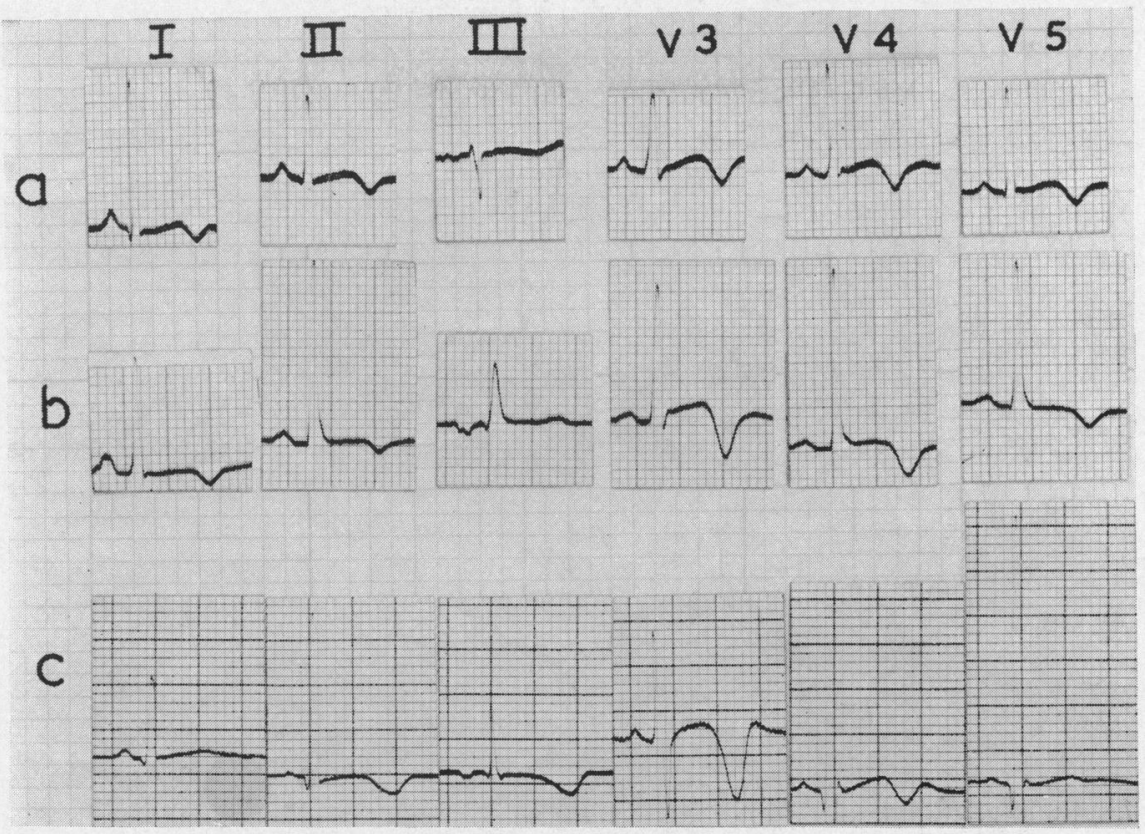

FIG. 4.-Grade IV cardiographic changes. Records at end of courses of S.A.T. (a) Case 49. European man, aged 27. (b) Case 55. Kuwaiti man, aged 28. (c) Case 18. Mauritian man, aged 22.

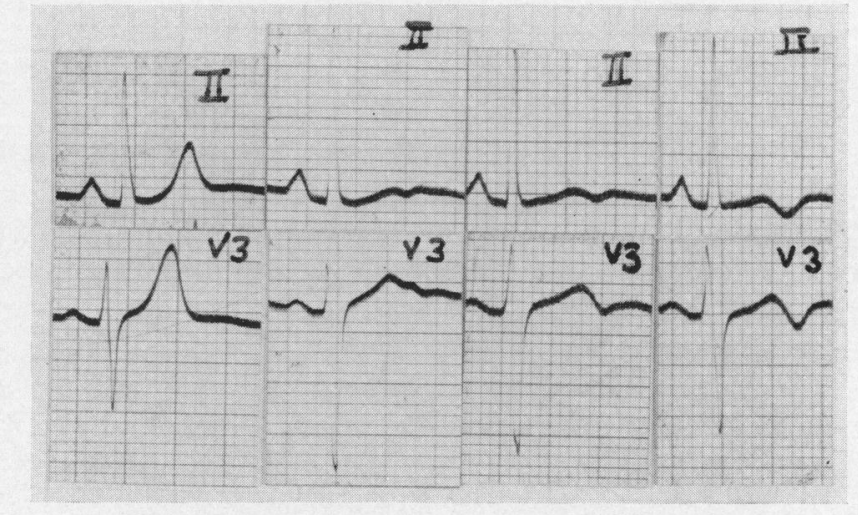

FIG. 5.-Serial cardiographs (upper, lead II; lower, lead V3) during treatment, showing increasing degree of abnormality, and finally grade IV cardiographic changes. (a) before treatment; (b) after $14 \frac{1}{2}$ grains $\left(0.94 \mathrm{~g}\right.$.); (c) after $24 \frac{1}{2}$ grains $(1.59$ g.); and $(d)$ after $30 \frac{1}{2}$ grains (1.98 g.). Case 45 . European man, aged 42.

in the standard leads and in V5 and V6, T may become flat or slightly biphasic (+-). Pari passu, changes occur in the S-T segment, most strikingly in the transitional zone V2 to V4: instead of being concave leading up to an upright $T$, the $S-T$ segment becomes straight, sloping up from a normally situated J (S-T take-off) to a lowered T. Characteristically, steep terminal dipping of the T wave occurs, with the terminal portion of $\mathrm{T}$ descending progressively further below the iso-electric line. This terminal negative phase of $\mathrm{T}$ may be accentuated by a prominent upright $\mathrm{U}$ wave immediately 
following it, and may in fact sometimes barely dip below the iso-electric level. Later, in cases more severely affected $\mathrm{T}$ becomes frankly inverted, sometimes very deeply, especially in V2 to V4: as it does so, the upward sloping S-T segment becomes less evident and S-T may become iso-electric again or become convex upwards, remaining slightly raised with the initial positive component of the biphasic $\mathrm{T}$ disappearing. $\mathrm{T}$ wave inversion, rarely very deep, tends to appear later in V5 and V6 and in the standard and unipolar limb leads; and upward sloping S-T segments are sometimes seen in these leads but are not so striking as in V2 to V4. No grossly elevated S-T plateaux such as occur in recent myocardial infarction have been seen, but $\mathrm{J}$ may become slightly raised.

In the standard leads, $T$ wave inversion is seen most frequently in lead III (30 patients), and much less commonly in lead I (11 patients), usually in association with severe changes in the præcordial leads; in one of these (Case 16) $\mathrm{T}$ in I was initially biphasic. T II became inverted in 20 patients, most of whom had severe changes in the præcordial leads. When the heart is electrically vertical and T in aVF and III strongly upright in the pre-treatment record, inversion of T III may be a relatively late feature and inversion of $\mathrm{T}$ in $\mathrm{I}$ and II relatively early.

In aVR, a normally inverted $\mathrm{T}$ becomes reduced in amplitude, then biphasic $(-+)$, and finally upright. In V1 there is most commonly a change in the same direction as in other leads (33 patients).

$U$ wave. In many records, particularly in the præcordial leads, prominent upright $U$ waves are seen, either interrupting the downslope of a broad low $\mathrm{T}$ or following an inverted $\mathrm{T}$ or the terminal negative portion of a diphasic T. U waves are commonly seen in the pre-treatment records, and often appear more obvious after treatment when a tall $\mathbf{T}$ has become lower, but in at least 20 patients the $U$ wave had undoubtedly become larger.

$Q-T$ duration. The Q-T duration has been difficult to measure reliably, particularly in the after treatment records. This is especially so when a prominent $U$ interrupts the downstroke of a low $\mathrm{T}$ or where a conspicuous $\mathrm{U}$ follows an inverted $\mathrm{T}$ or the negative phase of a biphasic $\mathrm{T}$. For comparison of Q-T before and after treatment in individual cases, the Q-Tc has been used.

There has been an undoubted increase in Q-Tc in the vast majority of cases. In 48, the increase was $0.04 \mathrm{sec}$. or more and this increase was greatest in those with the more severe grades of change, as judged by S-T and T. Fig. 6 shows the distribution of Q-T at the end of treatment, according to heart rate: only in three cases was it within normal limits.

Rate and Rhythm. No consistent change in pulse rate is seen. Sinus arrhythmia is naturally often seen in any records, but in two patients the degree of sinus arrhythmia became much greater during treatment. In Case $34(26 \mathrm{M}) \mathrm{RR}$ intervals varied between 0.66 and $1.02 \mathrm{sec}$. and in Case $25(35 \mathrm{~F})$, in whom severe $\mathrm{S}-\mathrm{T}$ and $\mathrm{T}$ wave changes developed, records showed gross variations of RR with extremes of 0.70 and 1.65 second. It is possible that the longest intervals were associated with sinus arrest or sinu-atrial block, but it seems likely that whatever the mechanism, there was increased vagal activity. Except in Case 1, no serious ventricular arrhythmia has been seen and no more than the occasional ventricular ectopic beat that may be seen in any normal record.

\section{The Classification of Electrocardiographic Changes}

In order to facilitate analysis of the factors influencing the severity of electrocardiographic changes observed, and to follow the progress of changes in the individual patient during and after treatment, an attempt has been made to classify the changes into the following five grades of severity.

Grade $O$. No change. Minimal reduction of $\mathrm{T}$ wave amplitude in a few leads may be associated with minimal increase in amplitude in other leads; such cases are classed with those in whom no change has occurred.

Grade I. Very slight change. Slight reduction in $\mathrm{T}$ wave amplitude, not exceeding $50 \%$ of initial height of $\mathrm{T}$, in all or several leads. The cardiogram usually remains within normal limits.

Grade II. Slight change (Fig. 2). Further reduction in amplitude of T wave, exceeding $50 \%$ of initial height of $\mathrm{T}$, in at least one limb and one præcordial lead. $\mathrm{T}$ in lead $\mathrm{I}$ often abnormal, i.e. less than $1 \mathrm{~mm} .(0 \cdot 1 \mathrm{mV})$. 
Grade III. Moderate change (Fig. 3). Upward sloping S-T segment with terminal dip in præcordial leads; $T$ is thus diphasic $(+-)$ or inverted with an initial slightly positive phase and dominant negative component. $\mathrm{T}$ in limb leads is very low, flat, or slightly diphasic; if the præcordial lead changes are relatively mild, cases with slight frank $\mathrm{T}$ wave inversion are included in this grade.

Grade IV. Severe change (Fig. 4 and 5). Frank T wave inversion in standard lead I or II and striking $\mathrm{T}$ wave inversion in præcordial leads. S-T segment may be upward sloping with terminal dip (and predominantly negative T) as in grade III, iso-electric or convex and slightly raised.

Grade V (Fig. 1). Serious ventricular arrhythmias (Case 1 only).

The changes observed do, of course, demonstrate a continuous gradation in severity and intermediate grades of severity may be difficult to classify. Difficulty arises particularly with cases showing straightening of the S-T segment in V2 to V4 and a terminal dip with little or no negative component of $\mathrm{T}$; and these have been classed as grade II. Also sometimes slight $\mathrm{T}$ wave inversion has been seen in the limb leads at a stage when præcordial $\mathrm{T}$ inversion is only relatively slight: these have been retained in Grade III. T wave inversion in III and aVF has been discounted in grading the severity of change for reasons already discussed, though it may be significant when the heart is electrically vertical. However, these criteria have proved satisfactory and useful in practice.

The significance of grade I changes must remain open to some doubt. Slight reduction in $\mathrm{T}$ wave amplitude may be due to normal physiological variations or to slight errors in standardization of sensitivity. Nevertheless, when the $\mathrm{T}$ waves are lower, even slightly, in most or all leads, particularly when further treatment leads to further reduction in voltage, it seems reasonable to attribute these slight changes to the treatment rather than to the factors just mentioned.

Distribution of Grades in the Whole Series (Table II). In the whole series, grade IV changes have been seen in 17 cases, grade III in 18, grade II in 22, and grade I in 1 case only. One patient alone (Case 33) has shown no change and at the other extreme only Case 1 has fallen into Grade V.

TABLE II

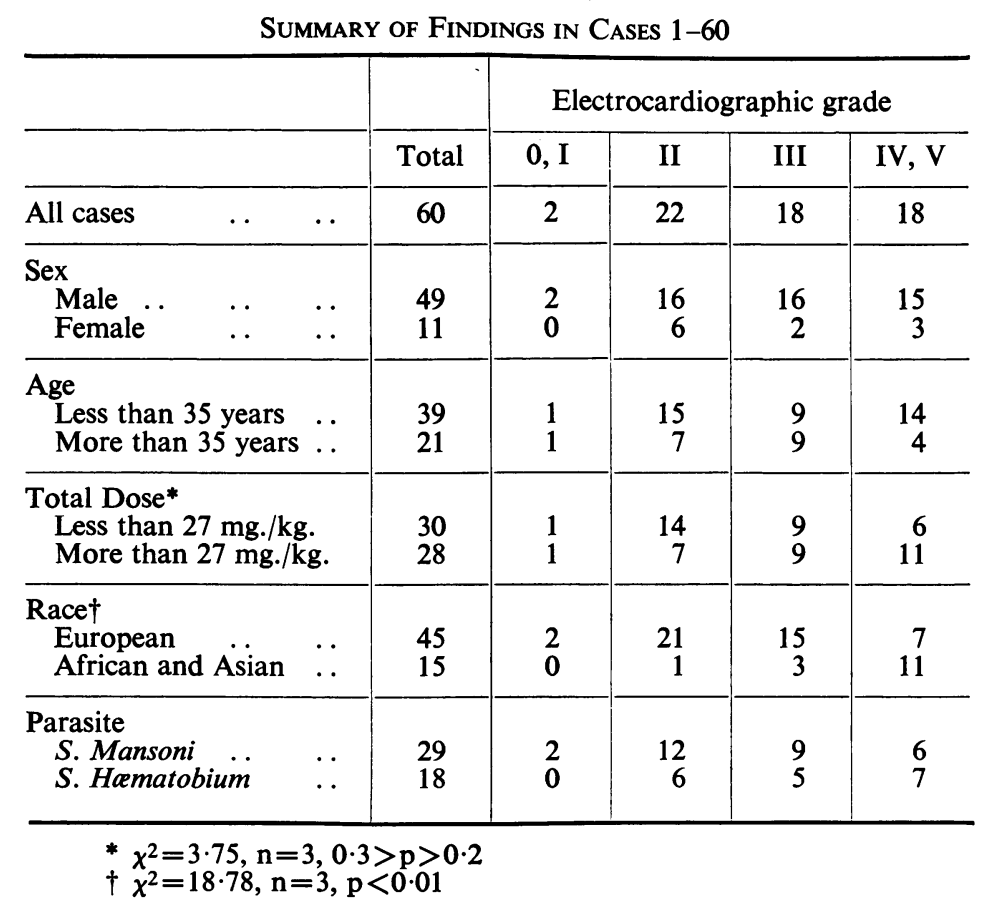

Relation of Severity of Change to Total Dose of S.A.T. A fairly constant dose was administered to most of the patients, who differed very widely in body weight. Only children were given much 
less than the usual dose and small adults a little less (Table I). The dose was not precisely related to body weight and therefore the resulting dose expressed in $\mathrm{mg}$. per $\mathrm{Kg}$. body weight has varied considerably ( 20.8 to $37.9 \mathrm{mg}$. $/ \mathrm{Kg}$.). It might be expected that the patients receiving the highest dosage would show the more severe grades of cardiographic change. It can be seen from Table II and Fig. 7 that there is no such close relationship, though with increasing grade of cardiographic change the average dose of S.A.T. does increase slightly and a higher proportion of the patients received more than $27.0 \mathrm{mg}$. $/ \mathrm{Kg}$.

Progress of Changes during Course of Treatment. Taking the series as a whole, there was no significant relation between total dose per unit body weight and degree of cardiographic change. But if the individual patient is considered (e.g. Case 45, Fig. 5) there was a progressive increase in severity of change during the course. In those developing grade IV cardiographic changes in whom serial records were obtained, these were graded and plotted against the dose of S.A.T. administered (Fig. 8); and this also demonstrates the gradual development of increasing severity of cardiographic abnormality during the course of treatment. In patients ultimately showing grade III or IV changes,

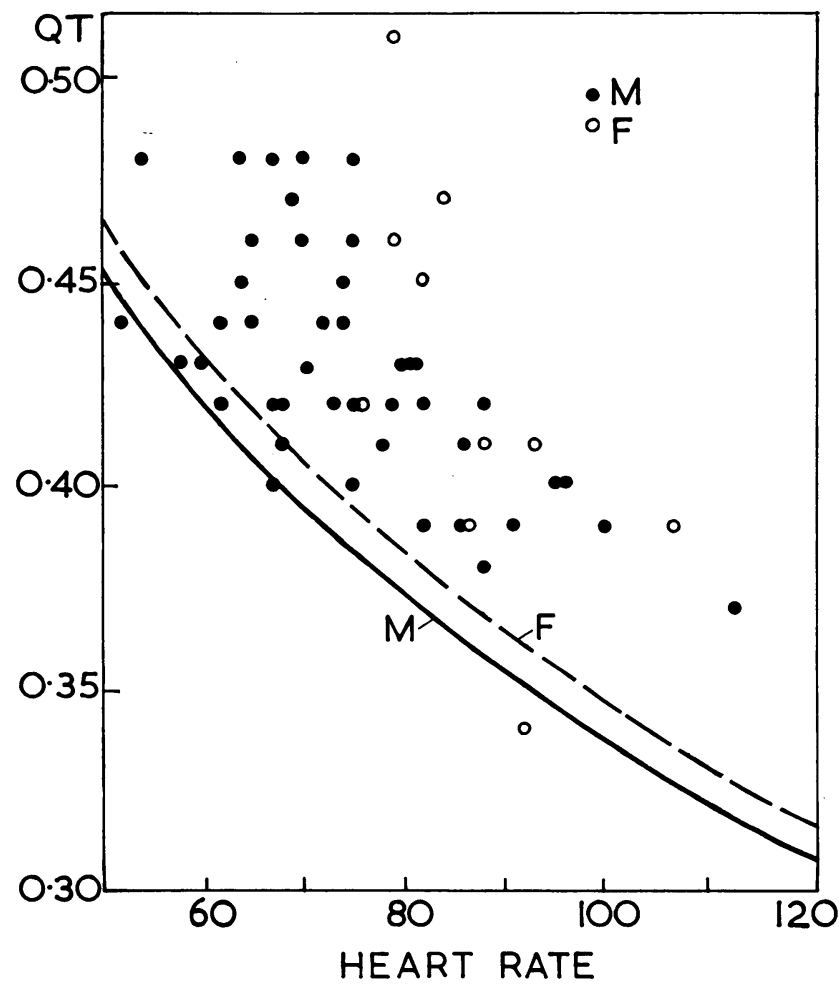

FIG. 6.-Q-T duration (plotted against heart rate) at the end of S.A.T. course. Continuous line denotes upper limits of normal for men and broken line upper limits of normal for women.

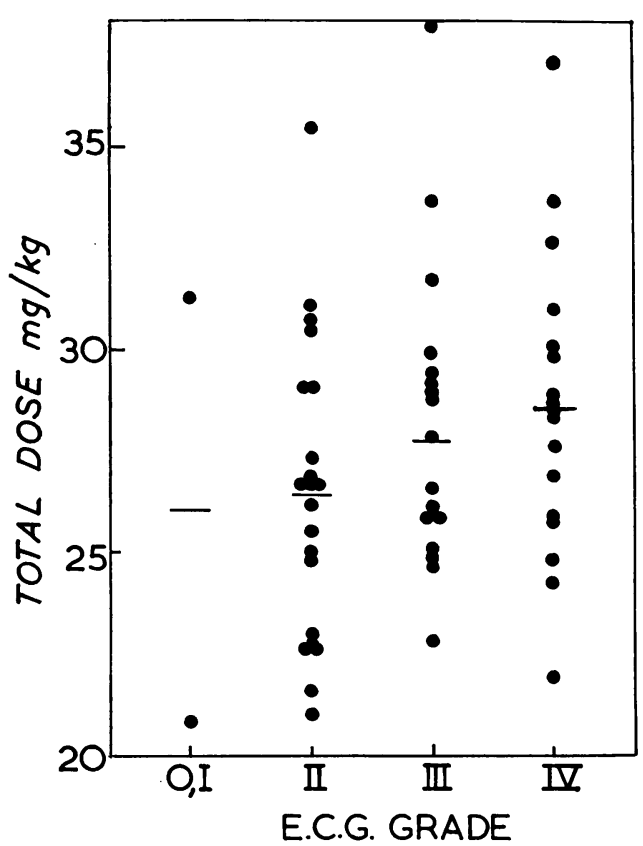

FIG. 7.-Total dose of S.A.T. (in mg. $/ \mathrm{kg}$. body weight) shown for each cardiographic grade. Short horizontal lines indicate the average for each grade, viz. $26.0 \mathrm{mg} . / \mathrm{kg}$. for grade $0-\mathrm{I}, 26.4 \mathrm{mg} . / \mathrm{kg}$. for grade II, $27.7 \mathrm{mg} . / \mathrm{kg}$. for grade III and $28.5 \mathrm{mg}$. $/ \mathrm{kg}$. for grade IV. These differences are not statistically significant (correlation coefficient $\mathbf{0} \cdot 212$, standard error $0 \cdot 132$ ).

significant (grade II) abnormalities may appear after as little as 3 grains ( $200 \mathrm{mg}$.) have been administered; grade III changes are frequently seen after 7-9 grains (450-600 mg.) and grade IV changes have occurred after as little as 13 grains $(850 \mathrm{mg}$.) and commonly after about 20 grains $(1 \cdot 3 \mathrm{~g}$.). The final degree of change may develop after about 20 grains $(1 \cdot 3 \mathrm{~g}$.) have been given, the cardiogram subsequently showing no further deterioration. The final degree of change depends less on the total dose given than on the factor of individual susceptibility. 


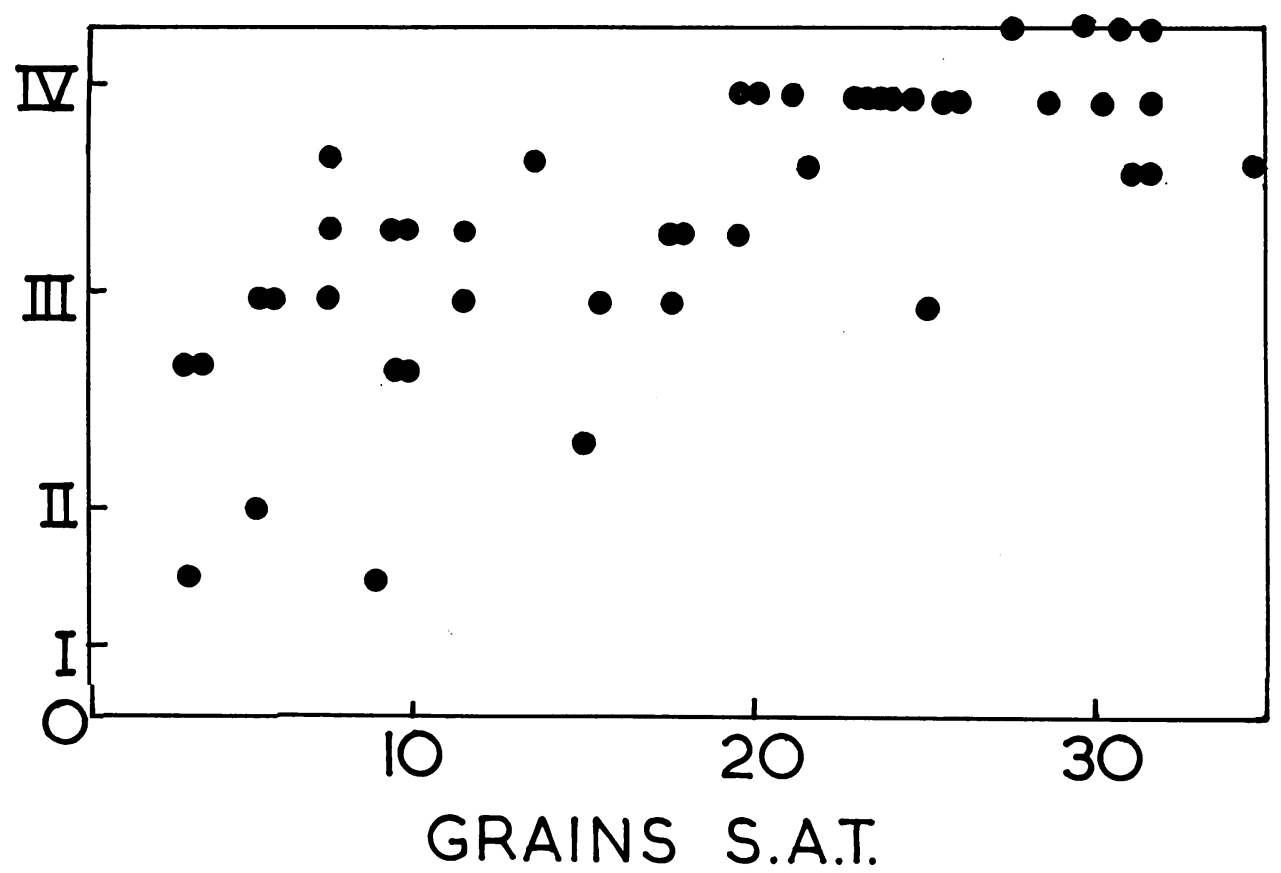

FIG. 8.-Development of cardiographic changes. The grade of change is plotted against dose of S.A.T. in those patients in whom serial records were made during the course of treatment and finally showed grade IV changes.

In this figure and the succeeding one, individual records have been classified as early, average, or late in each of the grades II, III, and IV in order to illustrate the increasing or decreasing severity of cardiographic changes more clearly.

Changes due to a Single Injection. In several patients daily records showed increasing severity of change from one day to the next. However, in the cases in whom cardiograms have been recorded immediately before and immediately after an injection, no change has been seen.

Regression of Changes after the End of the Course (Fig. 9). Cardiograms were recorded at various times after the end of the course in 38 patients, one of whom (Case 33) had shown no change on completion of the course of treatment. Thirty-one observations in 30 of these patients were made at the follow-up out-patient attendance between 4 and 9 weeks after the end of the course. Only 3 still showed mild grade II changes; 15 showed very slight (grade I) changes, and 13 had returned entirely to the normal pre-treatment state. Only 1 of 5 initially grade IV cases had returned to normal at 5-9 weeks. Only a few observations (6 records in 4 patients) were made in the early days and weeks after treatment, but these suggest that the changes regress fairly rapidly, so that by the end of 3 weeks, not more than slight (grade II) changes are to be expected. There are 5 observations (in 5 patients) at 10 weeks or more; 4 were normal and the fifth grade I (grade IV at end of course and grade I at 7 weeks). The very slight residual changes are of doubtful significance and the return to normal usually takes about 4-8 weeks, probably depending on the severity of the cardiographic abnormality at the end of the course.

Relation to Geographical Origin of Patients. Forty-five patients in the series were Europeans (including 1 American) who had lived overseas; 15 (including Case 1) were Africans and Asians (from Nigeria, Ghana, Sudan, Uganda, Mauritius, Iraq, and Kuwait). It soon became a strong impression that the latter group were far more prone than the Europeans to develop the more severe grades of change. In the final analysis this is shown clearly to be so (Table II) and the difference is highly significant. On the whole, the African-Asian group were lighter and received a higher dosage in 


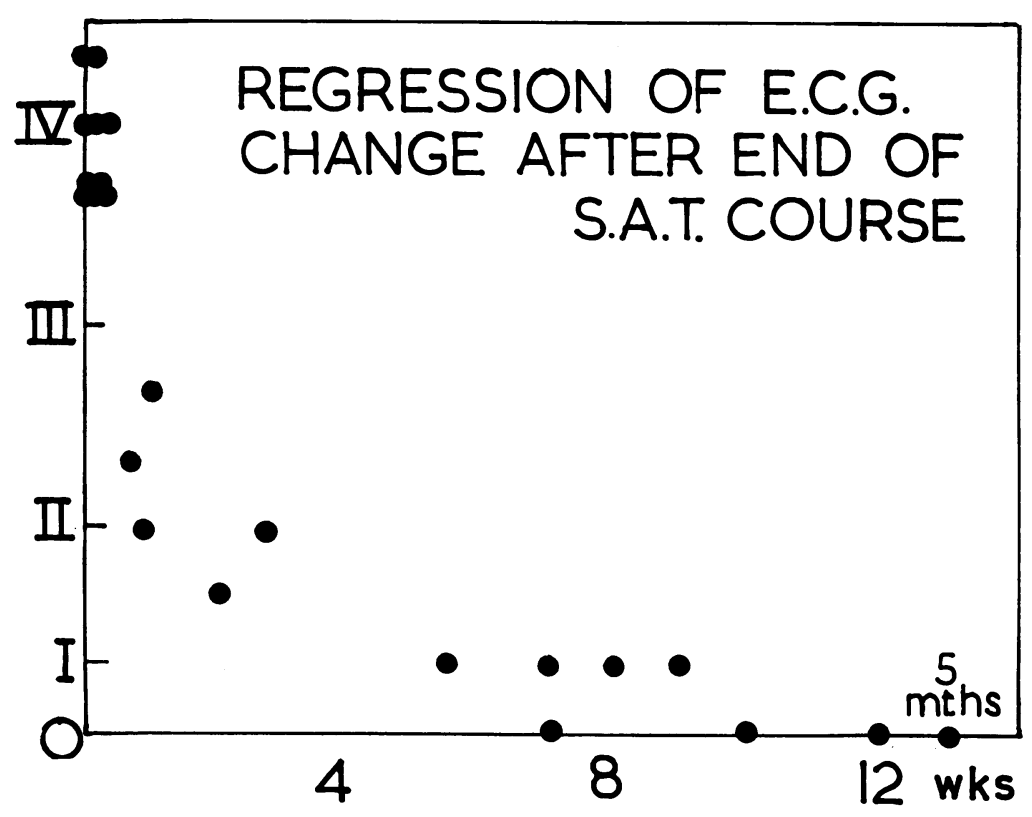

FIG. 9.- Regression of cardiographic changes. The grade of change is plotted against time (weeks) after the end of the S.A.T. course in patients in whom there were grade IV changes at the end of the course.

mg./Kg. body weight, but as there was no significant difference in dosage received by Europeans in the various cardiographic grades, this difference in weight cannot be held to account for the difference in susceptibility between Europeans and the African-Asian group. The African-Asian group is of course not ethnologically homogeneous, and in this small group one cannot say whether subjects of any particular racial origin are more susceptible than others.

Other Factors. There was no significant effect of age upon susceptibility (Table II); there was a suggestion that the older age group (35 years and over) was more likely to develop grade III or IV changes, but the difference was slight. Neither was sex a relevant factor (Table II); in spite of rather higher dose per unit weight in women, the changes seen were rather less than would be expected, but the difference was not more than could be explained by chance.

No significant difference was observed between patients infected with $S$. Mansoni and those with $S$. haematobium, whether the whole series or Europeans only were considered (Table II).

No correlation was observed between the intensity of non-cardiovascular side-effects and the severity of cardiographic change: some patients with the most severe changes tolerated the course well and others with much intolerance of the drug showed only slight abnormalities (including some in whom the treatment had to be discontinued).

Patients withdrawn from the series. Case 64. M, 57. British. Clinically normal C.V.S. Cardiogram before treatment normal. Treatment stopped by physician after 22.5 grains $(1.45 \mathrm{~g}$.) because of severe (grade IV) changes appearing after only $16 \cdot 5$ grains $(1 \cdot 17 \mathrm{~g}$.).

Case 65. M,37. British. Clinically normal C.V.S. History of rheumatic fever in childhood. Cardiogram before treatment normal. Immediately following third injection ( $1 \frac{1}{2}$ grains; total dose 3 grains) became grey with slow pulse and hypotension but no loss of consciousness. Treatment restarted after two days interval but after three further uneventful injections (grains $\frac{1}{2}, 1,1 \frac{1}{2}$ ) the next injection ( 2 grains; total dose 8 grains) was followed by a similar vaso-vagal episode. S.A.T. discontinued; course of nilodin (lucanthone) given. Cardiograms immediately after first episode and three days after the second, both grade I.

Case 66. F, 21. Nigerian. Clinically normal C.V.S.; soft pulmonary systolic ejection murmur presumed innocent. No history of rheumatic fever or chorea. Cardiogram before treatment normal, occasional ventricular ectopic beat. Twenty-three grains $(1.5 \mathrm{~g}$.) given in 12 days, tolerated well. Eighteen hours after 
last injection, called for bed-pan and was dead within three minutes. No other premonitory symptoms. No cardiograms recorded during treatment. At autopsy (Dr. J. D. Judah), there were the appearances of a very recent moderate-sized myocardial infarct in the posterior part of the septum, involving the whole thickness of the septum. The mitral valve was thickened and slightly stenosed. The coronary arteries were smooth, flexible, and widely patent. The bladder showed active Schistosomiasis and the abdominal lymphs nodes were enlarged. Histological examination revealed mild inactive rheumatic myocarditis and mitral valvulitis; no sections of the septal infarct were obtained. Tissue analyses for antimony were reported as follows: blood $0.017 \mathrm{mg}$. $/ 100 \mathrm{~g}$., liver $0.020 \mathrm{mg}$. $/ 100 \mathrm{~g}$., skeletal muscle $0.30 \mathrm{mg} . / 100 \mathrm{~g}$. and heart muscle $0.20 \mathrm{mg} . / 100 \mathrm{~g}$. (error $\pm 10 \%$ ).

Three patients (Cases 61, 62, and 63) discontinued treatment on account of non-cardiovascular side-effects. Another (Case 64), who was treated towards the end of the period of the investigation, showed severe cardiographic changes but no clinical evidence of cardiac damage; probably the withdrawal of the drug was a wise precaution (see discussion). In Case 65 there were typical examples of an early reaction, occurring early in the course of treatment and immediately after actual injections. The clinical picture as described by the doctor administering the injection suggested a vaso-vagal type of reaction. In Case 66, sudden death occurred at a time unrelated to an actual injection. The macroscopic appearances at autopsy were typical of a septal myocardial infarct and the coronary arteries were healthy. There was a mild inactive rheumatic carditis with involvement of the mitral valve, but this is unlikely to be related to the cause of death. Analyses demonstrated a concentration of antimony in the myocardium ten times that in the blood.

\section{Discussion}

There have been some previous reports of cardiographic changes during antimony treatment of schistosomiasis, in which standard leads have been recorded, sometimes with one or more bipolar præcordial leads (usually CR4 or CF4). Mainzer and Krause (1940) reported cardiograms in 12 patients undergoing treatment with tartar emetic: these showed decreased voltage, disappearance or inversion of $T$ waves, merging of S-T and T into a slightly convex line with an upward incline and, in a few, decreased QRS voltage and low, absent, or inverted P. Kenawy (1940) described lowering or slight inversion of T waves in one or more standard leads in 12 patients treated with rather small doses of tartar emetic or fouadin. Magalhaes and Dias (1944) found lowered or diphasic and occasionally slightly inverted T waves in 27 patients treated with relatively small doses of tartar emetic. Beaser and Rodriguez-Molina (1946), reporting cardiograms in 25 patients treated with fouadin, noted decreased amplitude of $\mathrm{T}$ in 20 , and "cove-plane" configuration of S-T and $\mathrm{T}$ in CF4 in two patients: in most, the record was normal again in three weeks.

Tarr $(1946,1947)$ studied 141 patients treated with fouadin or tartar emetic and reported four degrees of severity of $T$ wave change with decrease in voltage, lengthening of the proximal slope, slight negativity of the terminal portion, or sharply negative or cove-planed T. Slight or moderate prolongation of Q-T and iso-electric or inverted $P$ were seen in a few. Slowing of the pulse rate occurred in 77 . No adverse clinical effects were observed and there was no greater incidence of other toxic effects in those with maximal cardiographic change. Ninety-eight per cent of those treated with tartar emetic showed changes, 30 per cent being classified as +++ or ++++ . With fouadin, changes occurred less frequently, came on later during treatment, and were less severe. Recovery started within one week and was usually complete in 30-60 days.

Schroeder et al. (1946) studied 100 patients treated with fouadin or tartar emetic. The T wave became lowered, diphasic, or inverted, and in a few changed in contour; in CF4, a notch often appeared late in T, which became progressively deeper, producing a diphasic and finally deeply inverted $T$. In 45 per cent there was "fusion of the S-T segment with the $T$ wave". In a few $P$ became tall and pointed and $Q-T$ abnormally prolonged. Recovery was usually complete in five to seven weeks. Tartar emetic produced more severe changes than fouadin. Girgis and Aziz (1948), recording cardiograms in 16 patients treated intensively with S.A.T., found flattening or inversion of T, distinctly inverted in CR4 in all, and reduced amplitude of QRS in a third: recovery was still incomplete at eleven days. Suarez et al. (1948) reported 20 patients treated with anthiomaline: $\mathrm{T}$ became lower in all leads in 18 and inverted or diphasic in a few leads in some, but changes in the S-T segment were slight though Q-T was increased, not always beyond the normal range.

Chinese authors (Institute for Prevention and Treatment of Schistosomiasis, 1955) have also described lowering and inversion of $T$ waves in all of 100 patients treated with tartar emetic, and prolongation of Q-T in 94 per cent, and slight elevation or depression of S-T in 20 per cent. Ventricular arrhythmias, often associated with Stokes-Adams attacks, are frequently seen in China and characteristic cardiograms showing numerous multifocal ventricular ectopic beats and ventricular tachycardia have been published by Lu (1956) 
and T'ao Shou-Chi (1957). The latter also illustrated the cardiogram of a patient during a paroxysm of ventricular flutter-fibrillation lasting 97 seconds. Paroxysmal ventricular tachycardia and fibrillation, often fatal, was also reported by Huang Ming-Hsin et al. (1958) and Ch'en Yen-Yu et al. (1958).

These reports agree in emphasizing the frequency with which the $\mathrm{T}$ wave becomes reduced in amplitude, diphasic, or inverted, a finding amply confirmed in this study, in which particular attention has been paid to the præcordial V leads: here, the changes occur earlier and are more striking than in the limb leads. Changes in the S-T segment have been noted and have been described in various ways in several of the articles quoted: many illustrations in these papers show the changes described in the present study, though they are seen less well in the standard leads, with which previous reports have been mainly concerned. Changes in the $\mathrm{P}$ wave have been infrequently noted and are not of a consistent type. Though slowing of the pulse rate has been noted by some authors, this has not occurred in other series. The frequency of serious ventricular arrhythmias in China contrasts strikingly with absence of mention of them in other reports, but Case 1 of the present study resembles the Chinese cases very closely. Prolongation of Q-T is noted in some reports including the present one, but other authors find it in only a few of their patients.

In spite of the great differences in treatment schedule there is thus basic agreement about the essential S-T and T changes. Changes occur in virtually all cases with tartar emetic or S.A.T. but are less constant and less severe with fouadin or anthiomaline.

\section{Clinical Significance of the Cardiographic Changes}

Some previous workers reporting on these changes have regarded them as merely an interesting but unimportant by-product of antimony treatment (Tarr, 1946; Schroeder et al., 1946), basing this conclusion on the transience of the changes and their complete return to normal, and on the absence of any serious manifestations of cardiac damage in these patients. It is of course true that the occurrence of changes of pattern in the QRS-T complex signifies only a disturbance in the processes of depolarization and repolarization consequent on alterations in myocardial metabolism: though these may be harmless or even beneficial, it cannot be assumed that they are.

The cardiographic pattern in Case 1 was highly suggestive of myocardial infarction, lacking only pathological $Q$ waves which are by no means invariable in proven infarction. The $T$ wave inversion and upward sloping S-T segment seen in these cases is commonly seen in patients with cardiac pain due to coronary arterial disease. Reversible $\mathrm{T}$ wave inversion has been described and attributed to coronary spasm (East and Oram, 1948; Evans, 1955), slight coronary attacks (Papp and Shirley Smith, 1951), or septal infarction (Abrahams, 1957). Evans and McRae (1952) discuss terminal dipping of the $T$ wave among their lesser cardiographic signs of cardiac pain indicative of "restricted infarction". Brink and Goodwin (1952) describe reversible T wave inversion following the application of an icebag to the præcordium, and note that this is first seen in the terminal portion of $\mathrm{T}$ : they conclude that this terminal $\mathrm{T}$ inversion is associated with superficial injury, also adducing in support of this contention a patient with this pattern in whom autopsy revealed an area of fibrosis in the outer third of the left ventricular myocardium. Several illustrations in these papers clearly show upward-sloping S-T segments with terminal dipping or frank inversion of $\mathrm{T}$ exactly similar to those seen in the antimony cases; this is particularly so in two illustrations from Evans and McRae (1952) depicting "more obvious changes" in patients showing at other times the lesser cardiographic signs. Tarr's (1946) assertion that the changes due to antimony bear only a superficial resemblance to those of coronary disease is clearly untrue. The iso-electric S-T take-off and initial positive phase of $\mathrm{T}$ are in fact by no means uncommon in coronary disease, and the convex slightly elevated $\mathrm{S}-\mathrm{T}$ segment leading into a deeply inverted $\mathrm{T}$ seen in the more severe antimony cases is highly characteristic of fairly recent frank myocardial infarction, in which the so-called cove-planing is very familiar (Pardee, 1920). Low and inverted T waves may also occur in the more diffuse myocardial diseases (isolated myocarditis and the so-called cardiomyopathies), but in these low-voltage QRS complexes or left bundle-branch block are common (Wood, 1956; Brigden, 1957) and T wave inversion is rarely as deep as in some of the patients treated with antimony. 
Disturbance of potassium metabolism has also been suggested as a basis of the changes seen during treatment with tartar emetic (potassium antimony tartrate): however, the abnormalities described in this paper and in previous reports bear little resemblance to those usually seen in hypokalæmia (Bellet, 1955) and none to those of hyperkalæmia. There can, therefore, be no basis for the suggestion that alterations of intracellular or extracellular potassium are the main cause of the cardiographic changes.

Huang Ming-Hsin et al. (1958) regard the severe ventricular arrhythmias common in China as the effect of reflex vagotonia and increased myocardial irritability resulting from myocardial damage. The occurrence of bradycardia (Mainzer and Krause, 1940; Tarr, 1947) and of extreme sinus arrhythmia (in this study) affords some support for the presence of increased vagal activity in these cases. However, the $\mathrm{S}-\mathrm{T}$ and $\mathrm{T}$ wave changes are unlikely to be vagal in origin, as bradycardia is not always seen in those with the most change (Mainzer and Krause, 1940) and atropine, though producing tachycardia, does not reverse them (Tarr, 1947).

There would thus seem to be good grounds for believing the cardiogram of antimony administration to be indicative of coronary spasm or direct myocardial injury, possibly with patchy necrosis or limited infarction. The increased irritability is probably at least as important as the actual anatomical lesion in determining the outcome. In Case 1, severe cardiographic abnormalities were associated with a serious ventricular arrhythmia and a grave clinical condition with symptoms and signs pointing to a cardiovascular catastrophe: in fact, myocardial infarction was at first thought to be the correct diagnosis though she was young and a woman. This case provides valuable circumstantial evidence for the serious significance of the cardiographic change. No other direct evidence was obtained in this series, since fortunately such episodes are rare; the only patient (Case 66) who died, with macroscopic appearances suggestive of a lesion of the ventricular septum, was unfortunately not one selected for serial records. Plasma glutamic oxal-acetic transaminase (G.O.T.) estimations were performed (spectrophotometric method of Karmen, 1955) in Case 51 (grade IV cardiographic change) and in a patient treated with sodium antimony gluconate (grade II change) the results being 173 units $/ \mathrm{ml}$. and 110 units $/ \mathrm{ml}$. (normal 8-35 units). Though the plasma G.O.T. is a sensitive index of myocardial necrosis it may be raised to a greater extent in hepatitis. In patients on S.A.T. treatment, there may well be mild toxic hepatitis, even when this is not apparent clinically.

Study of the development and regression of the cardiographic changes during and after treatment strongly suggests that S.A.T. is a drug that exerts a cumulative action on the myocardium. The facts are best explained by supposing that following each injection, a proportion of the S.A.T. is taken up by the myocardium; and that, as the blood level falls, the myocardium gives up a small proportion of its antimony content, an appreciable concentration remaining at the time of the next injection. Ultimately equilibrium may be reached, when there is a high tissue concentration, the daily uptake and discharge of antimony being balanced. A similar suggestion has been made by Tarr (1947). In this sense, the behaviour of S.A.T. would resemble that of digitalis. Alves and Blair (1946) have found that in the 72 hours after starting an intensive 2-day course of S.A.T. only 18-28 per cent of the administered dose is excreted in the urine. Analysis of the blood and tissue antimony concentration in Case 66 also showed that considerable cumulation in the myocardium (and skeletal muscle) had occurred. That the degree of cardiographic change is not directly related to the blood level is demonstrated by the identity of the records immediately before and after an injection.

Sudden death or cardiovascular collapse may occur following an injection at any time during the course of treatment. This type of reaction appears to be due to idiosyncracy and is illustrated by Case 65 ; this patient had two episodes, clinically vasovagal, after a small total dose had been given, on each occasion when the daily dose had been increased to a higher level. It is unlikely that dangerous concentrations of antimony would have been reached so early in the course and indeed his cardiogram showed only very slight changes. There seems little reason to relate this type of reaction to the cardiographic changes or to a toxic effect of antimony on the myocardium. 
It is clear that though the cardiographic changes in an individual patient are progressive, at any rate until a certain point is reached, the final degree of abnormality depends rather on individual susceptibility than on total dose (expressed in terms of body weight); there is no doubt also that Africans and Asians are much more susceptible than Europeans. What is not certain is whether these susceptible patients possess a myocardium with a great affinity for antimony, whether their myocardial metabolism is more readily deranged by a given concentration of antimony, or whether the difference is merely that in them the cardiogram is a more sensitive index of metabolic disturbances than in the other patients. This last possibility is suggested by the known lability of the $T$ wave in the Negro (Littman, 1946) and Bantu (Grusin, 1954; Powell, 1959). On the other hand, it may be significant that of all the patients described (66 cases) the only two sustaining serious clinical cardiac damage were Africans (Cases 1 and 66). It also seems that the Chinese are unusually prone to develop serious ventricular arrhythmias (Lu, 1956; Ch'ien Teh and Lin Yu-K'un, 1957; T'ao Shou-Ch'i, 1957; Ch'en Yen-Yu et al., 1958; Huang Ming-Hsin et al., 1958), though this may be due in part to the poor general condition of many of the patients.

It is reasonable to accept as a working proposition that the more abnormal the cardiogram the more likely is the patient to develop serious signs of myocardial damage due to antimony. If that is the case, then the cardiogram has an important place in the control of treatment. It is not practicable to recommend that daily records should be obtained during treatment, even during the latter part of the course, but a sound practice would be to record a cardiogram after the administration of approximately $15-20$ gr. $(0 \cdot 9-1 \cdot 2$ g.) of S.A.T., which is the smallest dose found to be associated with severe (grade IV) changes. In Africans and Asians, the tendency would be to take this record rather sooner, and with Europeans, rather later. If this were found to show grade IV changes smaller injections should be given, the spacing of the injections increased, or the course finished rather earlier than originally planned. If grade III changes were seen, the course could be continued unmodified, but further records taken at fairly frequent intervals. It is naturally necessary to balance the importance of adequate treatment of a disease with serious long-term implications against the slight risks of fatality during treatment. The use of intravenous atropine in large doses in the treatment of severe ventricular arrhythmias, if these develop in spite of these precautions, as recommended by Ch'en Yen-Yu et al. (1958) and Huang Ming-Hsin et al. (1958), appears to be worthy of trial.

Sodium antimony tartrate or the corresponding potassium salt, tartar emetic, is obviously not an ideal drug in the treatment of schistosomiasis. Apart from these cardiac complications, the treatment is unpleasant and it is unusual for side-effects to be entirely absent. At least one group of fatalities appears to be associated with the tendency for the drug to accumulate in the heart muscle, and also incidentally in skeletal muscle, a property that is unlikely to have any therapeutic value. That only one death during treatment has occurred at the H.T.D. is a reflection not of the safety of the drug but of the care with which it is given and the type of patients treated. In contrast, the Chinese authors Ch'ien Teh and Lin Yu-K'un (1957) were able to collect 172 fatal cases, of whom 129 died from "toxic myocarditis". Three cases have been treated at the H.T.D. with sodium antimony gluconate (S.A.G.): all have shown similar cardiographic changes, though none of these three developed more than mild grade III changes, in spite of the course being shorter and more intensive than with S.A.T. $(2.36 \mathrm{~g}$. in 11 days; total Sb $727 \mathrm{mg}$.). Further experience is necessary to determine whether S.A.G. has less effect on the cardiogram and, by implication, a less toxic effect on the myocardium than S.A.T. Fouadin (stibophen) and anthiomaline produce less striking changes (Tarr, 1946, 1947; Schroeder et al., 1946; Suarez et al., 1948) but these drugs are certainly less effective therapeutically.

The toxic effect observed might not be due to the antimony compound as such but to some product of dying or dead schistosomes liberated by the antimony treatment, which might even be liberated by an unrelated schistosomocidal drug. This suggestion is unlikely to be correct: it could be tested by recording cardiograms during treatment of schistosomiasis with non-antimonial drugs but, since such drugs at present are thought to be considerably less effective, there is little 
justification for their use; or by recording cardiograms during treatment of other conditions with S.A.T. Schroeder et al. (1946) have observed similar but lesser changes during treatment of a few patients with leishmaniasis and filariasis with pentavalent antimonials.

\section{SUMmARY AND CONCLUSIONS}

A West African girl, aged 23, developed severe chest pain, circulatory collapse, and StokesAdams attacks at the end of a course of treatment with sodium antimony tartrate (S.A.T.). A cardiogram showed $\mathrm{S}-\mathrm{T}$ and $\mathrm{T}$ wave changes suggestive of myocardial infarction and also a ventricular tachycardia with bizarre multifocal QRS complexes. Complete clinical and electrocardiographic recovery followed.

Cardiograms of 59 patients receiving S.A.T. treatment were recorded before and after treatment. They showed reduction in amplitude of $\mathrm{T}$, characteristic upward sloping $\mathrm{S}-\mathrm{T}$ segment with terminal dipping and later frank $\mathrm{T}$ wave inversion, most frequently in the præcordial leads $\mathrm{V} 2$ to V4, and prolongation of the Q-T duration. These changes are divided into 4 grades of severity; one patient alone showed no change, one showed grade I change, 22 grade II, 18 grade III, and 17 grade IV changes. Severity of change is not closely related to age, sex, or total dose, but Africans and Asians are particularly prone to show more severe changes. Serial records show progressive increase in severity of change and, after treatment, gradual return to normal after six weeks or more.

The changes are attributed to cumulation of antimony in the myocardium producing metabolic and functional changes and possibly actual necrosis. They are regarded as being a sign of impending clinical myocardial damage with potentially serious or lethal consequences.

A second West African girl, aged 21, who died during treatment is described. No serial cardiograms were recorded, but autopsy revealed a septal infarct and a high concentration of antimony in the myocardium (Case 66).

It is suggested that until S.A.T. is supplanted by a safer but equally effective drug, a wise precaution is to record a cardiogram after the administration of $15-20$ grains $(0 \cdot 9-1 \cdot 2 \mathrm{~g}$.) and modify the course of treatment if severe changes are seen.

I wish to thank Dr. Kenneth Harris, in whose department the work was done, for suggesting this investigation and for his continued advice and encouragement, Sir George McRobert, Professor Woodruff, Dr. J. H. Walters, and Dr. F. D. Schofield, for their encouragement and permission to study patients under their care at the Hospital for Tropical Diseases. I also wish to thank the cardiographic technicians at University College Hospital, especially Miss E. M. Casey, who recorded most of the cardiograms reported here, and Dr. I. G. Holden, Principal Scientific Officer of the Metropolitan Police laboratory, for the post-mortem antimony analyses.

\section{REFERENCES}

Abrahams, G. (1957). Brit. Heart J., 19, 233.

Adams, A. R. D., and Maegraith, B. G. (1953). Clinical Tropical Diseases. Blackwell, Oxford.

Alves, W., and Blair, D. M. (1946). Lancet, 1, 9.

Ashman, R., and Hull, E. (1937). Essentials of Electrocardiography. Macmillan, New York.

Beaser, S. B., and Rodriguez-Molina, R. (1946). Amer. Heart J., 32, 634.

Bellet, S. (1955). Arch. intern. Med., 96, 618.

Brigden, W. (1957). Lancet, $2,1179$.

Brink, A. J., and Goodwin, J. F. (1952). Brit. Heart J., 14, 331.

Ch'en Yen-Yu and Wang Yu-Lien (1958). Chinese J. intern. Med., 6, 9 (abstr. in English, Chinese med. J. (1958), 76, 204).

Chi'en Teh and Lin Yu-K'un (1957). Chinese J. intern. Med., 5, 524 (abstr. in English, Chinese med. J. (1957), 75, No. 8).

Christopherson, J. B. (1918). Lancet, 2, 325.

, (1919). Lancet, 1, 1021.

East, T., and Oram, S. (1948). Brit. Heart J., 10, 263.

Evans, W. (1955). Brit. Heart J., 17, 15.

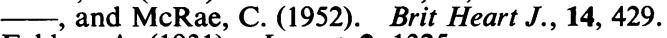

Fakhry, A. (1931). Lancet, 2, 1325.

Girgis, B., and Aziz, S. (1948). Lancet, 1, 206.

Goodman, L. S., and Gilman, A. (1956). The Pharmacological Basis of Therapeutics. Macmillan, New York.

Grusin, H. (1954). Circulation, 9, 860. 
Huang Ming-Hsin, Chiang Shao-Chi, P'an Ju-Sun, Yu Kuo-Juai, Lu Cheng-Wei, Hsu Chia-Yu, and Kao Wei-Shih (1958). Chinese med. J., 76, 103.

Institute for Prevention and Treatment of Schistosomiasis (1955). Chinese J. intern. Med., 3, 359. (abstr. in English, Chinese med. J. (1955), 73, 268.

Jopling, W. H. (1949). J. Trop. Med. Hyg., 52, 121.

Karmen, A. (1955). J. clin. Invest., 34, 131.

Kenawy, M. R. (1940). Gaz. Fac. Med. Cairo, 8, 161.

Khalil, M. (1935). J. Egypt. med. Ass., 18, 284.

Littman, D. (1946). Amer. Heart J., 32, 370.

Lu, C. H. (1956). Chinese J. intern. Med., 4, 449.

Mainzer, F., and Krause, M. (1940). Trans. Roy. Soc. Trop. Med. Hyg., 33, 405.

Magalhaes, B. F., and Dias, C. B. (1944). Mem. Inst. Oswaldo Cruz, 41, 363.

Manson-Bahr, P. (1954). Manson's Tropical Diseases. Cassell, London.

Papp, C., and Shirley Smith, K. (1951). Brit. Heart J., 13, 17.

Pardee, H. E. B. (1920). Arch. intern. Med., 26, 244.

Powell, S. J. (1959). Brit. Heart J., 21, 263.

Rail, G. A. (1949). Lancet, 1, 548.

Schofield, F. D. (1957). Personal communication.

Schroeder, E. F., Rose, F. A., and Most, H. (1946). Amer. J. med. Sci., 212, 697.

Suarez, R. M., Santiago-Stevenson, D., and Hernandez-Morales, F. (1948). Amer. Heart J., $36,923$.

T'ao Shou-Chi (1957). Chinese med. J., 75, 365.

Taran, L. M., and Szilagyi, N. (1947). Amer. Heart J., 33, 14.

Tarr, L. (1946). Bull. U.S. Army Med. Dept., 5, 336.

, (1947). Ann. intern. Med., 27, 970.

War Medicine (1945), 7, 397.

Wood, P. (1956). Diseases of the Heart and Circulation. 2nd ed., Eyre and Spottiswoode, London. 